\title{
Risk, balanced skills and entrepreneurship
}

\author{
Chihmao Hsieh • Simon C. Parker • \\ C. Mirjam van Praag
}

Accepted: 7 June 2016/Published online: 26 July 2016

(C) The Author(s) 2016. This article is published with open access at Springerlink.com

\begin{abstract}
This paper proposes that risk aversion encourages individuals to invest in balanced skill profiles, making them more likely to become entrepreneurs. By not taking this possible linkage into account, previous research has underestimated the impacts of both risk aversion and balanced skills on the likelihood individuals choose entrepreneurship. Data on Dutch university graduates provide an illustration supporting our contention. We raise the possibility that even risk-averse people might be suited to entrepreneurship; and it may also help
\end{abstract}

The authors, listed in alphabetical order, are grateful to Peter Berkhout for his contribution to the data analysis and Peter Thompson for helpful comments on an earlier draft. The usual disclaimer applies.

C. Hsieh

Yonsei University, UIC 406 Veritas Hall C, 85

Songdogwahak-ro, Yeonsu-gu, Incheon 406-840, South

Korea

e-mail: c.hsieh@yonsei.ac.kr

S. C. Parker

Western University, Ivey-New Building 2353, 1255

Western Road, London, ON N6G 0N1, Canada

e-mail: sparker@ivey.uwo.ca

C. M. van Praag

Copenhagen Business School, Frederiksberg, Denmark

C. M. van Praag $(\bowtie)$

University of Amsterdam, Postbus 15953,

1001 NL Amsterdam, The Netherlands

e-mail: mvp.ino@cbs.dk explain why prior research has generated somewhat mixed evidence about the effects of risk aversion on selection into entrepreneurship.

Keywords Entrepreneurship · Jack-of-all-trades · Risk · Human capital · Occupational choice - Balanced skills

JEL Classifications $\quad$ D81 $\cdot$ J24 $\cdot$ L26 $\cdot$ M13

\section{Introduction}

Two of the most influential theories of individual selection into entrepreneurship are based on the concepts of risk aversion, RA (Kihlstrom and Laffont 1979), and balanced skills, BS (Lazear 2005). Specifically, if entrepreneurship is a more risky occupation than paid employment, and if individuals vary in their aversion to risk, then it follows that the least riskaverse people are most likely to become the entrepreneurs (Kihlstrom and Laffont 1979). Moreover, because entrepreneurship requires expertise in a variety of roles while paid employment rewards specialists, people with balanced skills are most likely to become entrepreneurs as well (Lazear 2005).

Despite the prominence and continued influence of the RA and BS theories, the evidence for them is decidedly mixed. For example, many psychologybased studies have failed to detect any difference 
between entrepreneurs and non-entrepreneurs in terms of their risk attitudes (Brockhaus 1980; Shaver and Scott 1991). Meta-analyses of risk aversion and entrepreneurial selection have also generated conflicting results (Stewart and Roth 2001; Miner and Raju 2004), with Miner and Raju (2004) concluding that the available evidence about the validity of the RA theory is inconclusive. Economics-based studies have also generated mixed findings (Astebro et al. 2012). While some research suggests that entrepreneurs are indeed typically less risk-averse than employees (Cramer et al. 2002; Ekelund et al. 2005; Ahn 2010; Brown et al. 2011), others have reported insignificant differences between these groups (Barsky et al. 1997; Parker 2008). Still others have found an association between risk aversion and entrepreneurial entry ( $\mathrm{Si}$ mons and Astebro 2010), a non-monotonic relationship between risk aversion and the entrepreneur's work commitment (Elston et al. 2005), and a dependency of the relationship between risk aversion and entrepreneurship on other factors such as education (Polkovnichenko 2002). And while several studies have measured balanced skills in terms of the number of prior job roles, and have generated evidence consistent with the BS theory (Lazear 2005; Wagner 2006; Hartog et al. 2010; Astebro and Thompson 2011), the robustness of these results has been called into question (Silva 2007).

While RA and BS remain popular and influential theories, not least because of their persuasive and attractive internal logics, their lack of clear empirical support raises several troubling questions. For example, does the inconclusive evidence about the role of risk aversion mean that any differences of this sort do not actually affect occupational choice, perhaps because other factors dominate this choice (or because paid employment is also risky: Parker 1997)? Likewise, have the estimates of skill balance been weakened by using a flawed proxy, namely the number of prior job roles-or are they actually a mirage, masquerading as hard-to-measure personal abilities (Silva 2007; Hartog et al. 2010), or preferences such as a 'taste for variety' (Astebro and Thompson 2011)? Lacking answers to these questions, our knowledge about reasons why people become entrepreneurs is bound to remain limited.

This paper proposes a different argument which may shed light on this issue. Previous work has indeed examined the effects of both risk aversion and skill balance on the entrepreneurial entry decision, but treating them as independent variables (e.g., Lazear 2005: 672). We instead propose that balanced skills and risk aversion are not independent and should be studied and examined empirically in tandem. Given evidence that risk-averse actors like to diversify their human capital (e.g., Amihud and Lev 1981), one might expect highly specialized employees to be left with few competitive options if returns from specialism suddenly become less valuable in fast-changing, uncertain environments (Abernathy and Wayne 1974). Then risk-averse individuals who fear the loss of flexibility associated with highly specialized human capital may respond by diversifying their human capital investments. As a result, risk-averse people could ironically end up acquiring exactly the balanced skill sets which are especially conducive to entrepreneurship.

As well as being of interest in its own right, the possibility that risk aversion and balanced skills are positively related implies, as we go on to show, that empirical studies (which have ignored this interdependence hitherto) might have underestimated both of their impacts on entrepreneurial selection. In principle, this point might help to explain the mixed body of evidence pertaining to the RA and BS theories.

The paper makes the following contributions. First, it extends our theoretical understanding of entrepreneurship as an occupational choice by proposing a novel association between the two hitherto separate concepts of risk aversion and balanced skills. Our simple formulation extends the theory of BS from a certain environment (as in Lazear 2005) to a risky one. Risk is present in both occupations; and the acquisition of balanced skills is treated as a choice variable in our theory, rather than being taken as given as in Lazear (2005).

Second, our theorizing proposes a richer empirical specification of career choices between entrepreneurship and wage employment, which is estimated using a sample of recent graduates from Dutch universities. The dataset has several attractive properties. One is that, in line with our theory, the survey respondents (who are sampled shortly after graduation) are homogeneous in terms of their education levels and labor market experience. Consequently, differences in human capital between individuals pertain (almost) exclusively to skills balance, rather than to skills levels. We deem this an advantage given 
Polkovnichenko (2002) insight that the risk of entrepreneurship is lower when human capital is greater, since human capital is homogeneous in our dataset. Another interesting aspect of the dataset is that it enables us to depart from the conventional practice of proxying skills balance by the variety of prior labor market experience. The latter may be associated with unobserved abilities (Silva 2007). Instead, we propose a novel measure of skills balance based on the observed multi-industry versatility of degree majors. Thus, consistent with our theory, skills balance is measured prior to when occupational choices are observed, thereby avoiding problems of reverse causality. However, we acknowledge upfront that we are not able to eliminate common causation by an unobservable individual-fixed variable. This weakness remains with the field.

Third, the paper provides a platform for re-evaluating mixed prior evidence from tests of the RA and BS theories. It assesses empirically the implications of omitting each of risk aversion and skill balance measures from empirical models of entrepreneurship and quantifies the biases that can result therefrom.

The next section outlines a simple model of skill balance acquisition and occupational choice. The sections that follow describe the empirical methods and data, before presenting the empirical results. The final section highlights some of the study's limitations and concludes.

\section{The model}

There is a unit mass of atomistic decision-making individuals. There are two occupations, paid employment (P) and entrepreneurship (E), and two skills which generate returns in both occupations, $x_{1}$ and $x_{2}$. To abstract from issues of aggregate skill acquisition, which is not of interest here, assume that every agent obtains a unit endowment of total skill. This allows us to use the more compact notation $x_{1}=x$ and $x_{2}=$ $1-x$ hereafter. In $\mathrm{E}$, both skills are needed for any output to be produced, whereas in $\mathrm{P}$, workers can specialize in one skill. People specialize if they choose $x^{*}=1$ or $x^{*}=0$. If $0<x^{*}<1$ they choose some mixture of skills. The production technology which maps $x$ and $1-x$ into returns differs in each occupation, as described below.
The timing of events is as follows. Reflecting the timing of choices in students' lives, first in formal education and then in the workforce, the model comprises two stages. At stage one, individuals first undergo schooling, at which point $x$ is chosen. Here we simply observe that $x$ is defined in terms of the balance of formal subject choices and the number of jobs which majors in those subjects open students up to (precise definitions are deferred to the data section below). Students do not yet know their idiosyncratic ability in either occupation; nor do they know their future stochastic returns given those abilities. There are therefore two sources of risk: 'idiosyncratic' risk (i.e., risk relating to the levels of their own abilities) and 'market' risk (i.e., risk relating to the returns to those abilities). Students choose $x$ ex ante, i.e., before they know which occupation they will enter after leaving school. However, they use all of the available information when choosing $x$, namely the probabilities $p$ and $1-$ $p$ of eventually working in $\mathrm{P}$ and $\mathrm{E}$, respectively. Once students have determined their optimal $x$, denoted $x^{*}$, its value is fixed thereafter. Since (as noted above) we will be measuring $x$ in terms of educational skill balance, this modeling assumption also matches the data at hand.

At stage two, students graduate and enter the workforce. At this point, their abilities in the two occupations are revealed. This resolves their idiosyncratic risk-though their market risk remains. Only now do they have enough information to make their $e x$ post occupational choice, which is conditioned on their $x^{*}$ determined at stage one.

First the model is outlined for the case of certainty. This is the case analyzed by Lazear (2005) and others. We then extend the (stage one) analysis to the case of risk, analyzing the problem of choosing $x$ to maximize ex ante expected utility. Finally, we analyze ex post (stage two) occupational choices.

Certainty Suppose specialization in $x=1$ yields the return $\omega_{1}$ in $\mathrm{P}$, while specialization in $x=0$ yields return $\omega_{2}$ in $\mathrm{P}$. According to Lazear (2005), $y^{\mathrm{P}}=\max \left\{\omega_{1}, \omega_{2}\right\}$. Hence workers do best specializing in one skill or the other: $x^{*} \in\{0,1\}$. In E, Lazear's return function is $y^{\mathrm{E}}=\theta \min \{x, 1-x\}$ for $\theta>1$, so entrepreneurs do best if they have balanced skills: $x^{*}=\frac{1}{2}$. 
For tractability, we will use generalized versions of Lazear's specifications which do not predetermine $x$ choices by assumption - and, more importantly, which enable the model to be extended tractably to deal with the case of risk. We will first show that our specifications generate the same results in the case of certainty. Our specifications of the returns in each occupation are:

$$
\begin{aligned}
& y^{\mathrm{P}}(x)=\omega_{1} x+\omega_{2}(1-x) \\
& y^{\mathrm{E}}(x)=\theta x(1-x) .
\end{aligned}
$$

In the benchmark case of certainty considered by Lazear (2005), all parameters in the set $\Omega:=$ $\left\{\omega_{1}, \omega_{2}, \theta\right\}$ are positive. It follows immediately that workers do best with $x=1$ if $\omega_{1}>\omega_{2}$ and with $x=0$ if $\omega_{1}<\omega_{2}$ (either solution is equally good if $\omega_{1}=\omega_{2}$ ). Entrepreneurs do best with $x=\frac{1}{2}$. Hence employees specialize in one skill while entrepreneurs have balanced skills. Provided $\theta>4 \max \left\{\omega_{1}, \omega_{2}\right\}$, individuals with balanced skills do best in $\mathrm{E}$, whereas those possessing specialized skills do best in P. These predictions mirror Lazear's.

Risk Now we move into more novel territory by examining the roles of risk and risk preferences. Consider the standard utility function

$U(y)=-\mathrm{e}^{-\lambda y}, \lambda>0$

where $\lambda$ is the coefficient of absolute risk aversion (ARA). To introduce idiosyncratic and market risk at stage one, make $\Omega$ stochastic, with $\omega_{1} \sim N\left(\mu_{1}, \sigma^{\mathrm{P}}\right)$, $\omega_{2} \sim N\left(\mu_{2}, \sigma^{\mathrm{P}}\right)$ and $\theta \sim N\left(m, \sigma^{\mathrm{E}}+\psi\right)$ ex ante. Thus, consistent with the bulk of the entrepreneurship literature, we assume that market risk is concentrated in entrepreneurship, through the variance term $\psi>0$ : market risk is never resolved and cannot be insured against. ${ }^{1}$ However, all abilities are prone to idiosyncratic risk, as reflected in the $\sigma$ variance components. At stage one, a student uses this information to calculate ex ante expected utility as

\footnotetext{
$\overline{1}$ All agents are assumed to know the parameters of all of these normal distributions ex ante, which all have positive means and variances. Similar results obtain if $\omega_{1}$ and $\omega_{2}$ also include modest amounts of market risk; we suppress this complication for simplicity.
}

$$
\max _{x}\left\{p(x) E U\left(y^{\mathrm{P}}\right)+(1-p(x)) E U\left(y^{\mathrm{E}}\right)\right\},
$$

where $p(x)$ and $1-p(x)$ are a student's subjective probabilities of subsequently entering $\mathrm{P}$ and $\mathrm{E}$, respectively. (It will be seen below that these probabilities generally depend on $x$.) Once idiosyncratic risk is resolved at stage two, students finally choose their occupation. As is well known, the combination of normally distributed payoffs with constant ARA utility (3) gives rise to simple mean-variance utility expressions (see, e.g., Sargent 1987: 154-155). So the problem (4) can be rewritten as

$$
\begin{array}{rl}
\max _{x} & p(x)\left[\mu_{1} x+\mu_{2}(1-x)-\left(\lambda \sigma^{\mathrm{P}} / 2\right)\left(x^{2}+(1-x)^{2}\right)\right] \\
+(1-p(x))\left[m x(1-x)-(\lambda / 2)\left(\sigma^{\mathrm{E}}+\psi\right) x^{2}(1-x)^{2}\right]
\end{array}
$$

We can now form the ex ante (i.e., stage one) subjective probability that $\mathrm{P}$ is preferred to $\mathrm{E}$. Returns to skills are $\bar{\mu}_{1}=\mu_{1}+a_{1}, \quad \bar{\mu}_{2}=\mu_{2}+a_{2}$ and $\bar{m}=m+b$ : students do not know the values of $a_{1}$, $a_{2}$ and $b$ but know they are normally distributed with means zero and variances $\sigma^{\mathrm{P}}, \sigma^{\mathrm{P}}$ and $\sigma^{\mathrm{E}}$, respectively. Hence the ex ante probability that $\mathrm{P}$ will be preferred to $\mathrm{E}$ after idiosyncratic risk is resolved is:

$$
\begin{aligned}
p(x)= & \operatorname{Pr}\left[E U\left(y^{\mathrm{P}}\right) \geq E U\left(y^{\mathrm{E}}\right)\right] \\
= & \operatorname{Pr}\left[a_{1} x+a_{2}(1-x)-b x(1-x) \geq m x(1-x)\right. \\
& \left.-\mu_{1} x-\mu_{2}(1-x)-(\lambda \psi / 2) x^{2}(1-x)^{2}\right] \\
= & 1-\Phi(\Upsilon(x)),
\end{aligned}
$$

where $\Phi(\cdot)$ is the cumulative distribution function of the standard normal distribution (with density function $\phi$ ) and

$$
\Upsilon(x):=\frac{m x(1-x)-\mu_{1} x-\mu_{2}(1-x)-(\lambda \psi / 2) x^{2}(1-x)^{2}}{\sqrt{\sigma^{\mathrm{P}}\left(x^{2}+(1-x)^{2}\right)+\sigma^{\mathrm{E}} x^{2}(1-x)^{2}}} .
$$

The first- and second-order conditions for problem (5) are, respectively,

$$
\begin{aligned}
J_{1}= & {[1-\Phi(\Upsilon(x))]\left[\mu_{1}-\mu_{2}+\lambda \sigma^{\mathrm{P}}-2 \lambda \sigma^{\mathrm{P} x}\right] } \\
& +\Phi(\Upsilon(x))(1-2 x)\left[m-\lambda\left(\sigma^{\mathrm{E}}+\psi\right) x(1-x)\right] \\
& +\phi(\Upsilon(x))\left[E U\left(y^{\mathrm{E}}\right)-E U\left(y^{\mathrm{P}}\right)\right] \frac{\partial \Upsilon(x)}{\partial x}=0
\end{aligned}
$$




$$
\begin{aligned}
J_{2}= & -[1-\Phi(\Upsilon(x))] 2 \lambda \sigma^{\mathrm{P}}-\Phi(\Upsilon(x))\left[2 m+\lambda\left(\sigma^{\mathrm{E}}+\psi\right)\right. \\
& \times(1+6 x(1-x))]+2 \phi(\Upsilon(x)) \frac{\partial \Upsilon(x)}{\partial x} \frac{\partial}{\partial x} \\
& \times\left[E U\left(y^{\mathrm{E}}\right)-E U\left(y^{\mathrm{P}}\right)\right] \\
& +\left[\phi^{\prime}(\Upsilon(x))\left(\frac{\partial \Upsilon(x)}{\partial x}\right)^{2}+\phi(\Upsilon(x)) \frac{\partial^{2} \Upsilon(x)}{\partial x^{2}}\right] \\
& \times\left[E U\left(y^{\mathrm{E}}\right)-E U\left(y^{\mathrm{P}}\right)\right]
\end{aligned}
$$

In the following, we analyze the comparative statics for an agent who is indifferent $e x$ ante between $\mathrm{E}$ and P. For these agents $E U\left(y^{\mathrm{E}}\right)-E U\left(y^{\mathrm{P}}\right)=0$ so the final term of (6) equals zero. This leaves only the first line of (7) in the second-order condition, which is certainly negative, guaranteeing a maximum for this problem.

We make the following assumption of a lower bound on the idiosyncratic risk in occupation P:

Assumption $1 \sigma^{\mathrm{P}}>\left(\sigma^{\mathrm{E}}+\psi\right) / 4$.

Proposition 1 If Assumption 1 holds, greater risk aversion is associated with a more balanced skill profile among agents who are indifferent ex ante between $E$ and $P$.

Proof Implicit differentiation of (6) yields

$$
\begin{aligned}
\frac{\partial x^{*}}{\partial \lambda}= & -\frac{1-2 x}{J_{2}}\left[(1-\Phi(\Upsilon(x))) \sigma^{\mathrm{P}}\right. \\
& \left.-\Phi(\Upsilon(x))\left(\sigma^{\mathrm{E}}+\psi\right) x(1-x)\right] .
\end{aligned}
$$

For an indifferent agent $\Phi=1 / 2$ so Assumption 1 is sufficient to ensure the square bracketed term is positive. Given $J_{2}<0$, the sign of the derivative in (8) then depends on $x$ via the term $1-2 x$. By inspection, this derivative is large and positive when $x^{*}=0$ and decreases toward zero from above as $x^{*} \rightarrow 1 / 2$. Conversely it is large and negative when $x^{*}=1$ and increases toward zero from below as $x^{*} \rightarrow 1 / 2$. This proves the proposition.

Assumption 1 plays an important role because it encourages risk-averse people to choose balanced skills when they take into account the possibility that at stage two they might be in P. If Assumption 1 did not hold, risk-averse people could do better by choosing unbalanced skills, and taking their chances in P.

Stage 2 We now analyze the ex post occupational choice problem at stage two, when students graduate and enter the workforce. Unlike market risk, which always remains, idiosyncratic risk is now resolved: individual-specific mean returns to ability are revealed to be $\bar{\mu}_{1}, \bar{\mu}_{2}$ and $\bar{m}$. Thus $\omega_{1}$ and $\omega_{2}$ are no longer stochastic, being $\bar{\mu}_{1}$ and $\bar{\mu}_{2}$, respectively; $\theta$ remains stochastic but now with $\theta \sim N(\bar{m}, \psi)$. Each individual makes their occupational choice under conditions of market risk and conditional on $x^{*}$.

Proposition 2 All else equal, an individual with a more balanced skill profile is more likely than an individual with a less balanced skill profile to choose occupation E over P.

Proof Denote by $\hat{x}$ the values of $x$ which make individuals indifferent between $\mathrm{P}$ and $\mathrm{E}$ :

$$
\bar{\mu}_{1} \hat{x}+\bar{\mu}_{2}(1-\hat{x})=\bar{m} \hat{x}(1-\hat{x})-\lambda \psi \hat{x}^{2}(1-\hat{x})^{2} / 2 .
$$

The LHS of (9) is linear in $\hat{x}$, while the RHS is a $\cap$ shaped quadratic in $\hat{x}$, with its maximum at one half. Hence the probability that $\mathrm{E}$ is preferred to $\mathrm{P}$ is maximized with balanced skills. If the LHS and RHS intersect, there are two solutions to (9), denoted by $\left(\hat{x}_{1}, \hat{x}_{2}\right)$. Everyone with ex ante choices $x^{*}<\hat{x}_{1}$ or $x^{*}>\hat{x}_{2}$ chooses $\mathrm{P}$, while everyone with $\hat{x}_{1} \leq x^{*} \leq \hat{x}_{2}$ chooses E. Hence more balanced skills are associated with the choice of $\mathrm{E}$ over $\mathrm{P}$ in an occupational choice equilibrium.

Proposition 2 suggests that Lazear's well-known occupational choice result extends to the new domain of risky returns in paid employment and entrepreneurship. Finally, we examine the effects of risk aversion on occupational choice. Changes in $\lambda$ have 'direct' and 'indirect' effects on occupational choice. The direct effect relates to risk averters' dislike of payoff variance. The indirect effect relates to the impact on skill profiles (Proposition 1) which affect mean returns. The following proposition states the result:

Proposition 3 (a) The direct effect of risk aversion on occupational choice is to promote P over E; (b) The indirect effect of greater risk aversion is to promote $E$ over $P$.

Proof (a) The direct effect of an increase in $\lambda$ on occupational choice can be seen by inspection of (9). A greater $\lambda$ decreases the height of the quadratic return function in $\mathrm{E}$ without affecting its skew. This increases 
$\hat{x}_{1}$ and decreases $\hat{x}_{2}$, so the likelihood of $\mathrm{E}$ being preferred to $\mathrm{P}$ decreases.

(b) Proposition 1 established that the indirect effect of greater $\lambda$ on balanced skills is positive for individuals who are on the occupational choice margin $e x$ ante. Proposition 2 established that a more balanced skill set increases the attractiveness of $E$ relative to $\mathrm{P}$ - whence the result follows.

Proposition 3 suggests that balanced skills have subtle implications for the effects of risk aversion on ex post occupational choice. On the one hand, when market risk is present, the direct effect of risk aversion induces risk-averse people to choose paid employment over entrepreneurship. This is the well-known effect studied in previous research. On the other hand, because greater risk aversion encourages people facing idiosyncratic risk to acquire more balanced skill sets ex ante, and because balanced skills are more valuable in entrepreneurship ex post, greater risk aversion also serves to eventually make entrepreneurship more attractive relative to paid employment through the indirect balanced skills channel. ${ }^{2}$ An empirical analysis of risk aversion and balanced skills in entrepreneurship needs to take account of these distinct mechanisms.

\section{Empirical methodology and data}

\subsection{Empirical methodology}

Empirical analyses of entrepreneurship as an occupational choice usually utilize regressions which include either risk aversion or balanced skills variables, but not both. Below, we first outline the implications for tests of the RA and BS theories when one or other of

\footnotetext{
${ }^{2}$ Notice the importance of idiosyncratic risk and the two-stage model structure for generating this result. If in contrast individuals had been modeled to choose $x^{*}$ simultaneously with their occupation, then the Envelope Theorem would make the indirect effect zero. To see this, label the difference between the LHS and RHS terms in (9) as $z$ : then the derivative of the indirect effect is:

$\frac{\partial z^{*}}{\partial \lambda}=\frac{\partial z^{*}}{\partial x^{*}} \frac{\partial x^{*}}{\partial \lambda}$.

This would equal zero since the first-order condition would be $\frac{\partial z^{*}}{\partial x^{*}}=0$.
}

the variables measuring risk aversion or balanced skills is omitted. We also explain our empirical strategy for testing the Propositions developed in the previous section when both variables are present.

Consider the following equation to be estimated using a sample of individuals $i$ :

$$
z_{i}^{*}=\beta_{0}+\beta_{1} \lambda_{i}+\beta_{2} \mathrm{SB}_{i}+\beta_{3} X_{i}+u_{i} \quad i=1, \ldots, n
$$

where $z_{i}^{*}$ is a latent variable underlying a binary occupational choice variable such that

$z_{i}= \begin{cases}1 & \text { if } \mathrm{i} \text { chooses entrepreneurship: } \mathrm{z}_{\mathrm{i}}^{*}>0 \\ 0 & \text { if } \mathrm{i} \text { chooses paid employment: } \mathrm{z}_{\mathrm{i}}^{*} \leq 0\end{cases}$

Here $\lambda_{i}$ and $\mathrm{SB}_{i}$ are individual-level measures of risk aversion and skill balance, respectively; $X_{i}$ are a set of orthogonal control variables and $u_{i}$ is a disturbance term. According to Proposition $1, \lambda_{i}$ and $\mathrm{SB}_{i}$ are directly related; let $\gamma>0$ denote the coefficient of proportionality.

In terms of (10), Proposition 2 predicts $\beta_{2}>0$, while Proposition 3(a) predicts $\beta_{1}<0$. We can now deduce the bias that will occur if $\lambda_{i}$ or $\mathrm{SB}_{i}$ are omitted from (10). First, consider the case where $\mathrm{SB}_{i}$ is omitted. Then a standard result in econometrics (e.g., Greene 2003) is that the bias from estimating $\beta_{1}$ is $\gamma \beta_{2}$-which is positive. Hence estimates of the risk aversion effect on choice for entrepreneurship will be upward biased, i.e., biased toward zero if $\beta_{1}<0$. This might explain why some studies which analyzed only risk aversion and not balanced skills found small or insignificant effects of risk aversion on entrepreneurial selection. Second, consider the case where $\lambda_{i}$ is omitted. Now the bias from estimating $\beta_{2}$ is $\gamma \beta_{1}$, which is negative. Hence estimates of the balanced skills effect on choice for entrepreneurship will be downward biased, i.e., biased toward zero.

Our empirical strategy is as follows. First, we examine whether $\mathrm{SB}_{i}$ and $\lambda_{i}$ are positively related by using OLS to estimate $\gamma$ in a regression of $\mathrm{SB}_{i}$ on $\lambda_{i}$. This tests Proposition 1. Second, we estimate the effects of $\mathrm{SB}_{i}$ and $\lambda_{i}$ by applying probit methods to (10) and (11). This tests Propositions 2 and 3(a). In each of these cases, we also take account of the possibility that skill balance and unobservables affecting occupational choices are more similar within degree fields than between them. We do so by 
additionally reporting clustered standard errors by degree field $j(j=40)$. We also provide estimates using robust estimation techniques to correct for heteroskedasticity.

Third, we statistically test the biases predicted above, which can be summarized as $\beta_{1}<\left[\beta_{1} \mid \beta_{2}=0\right]$ and $\beta_{2}>\left[\beta_{2} \mid \beta_{1}=0\right]$. This tests Proposition 3(b). Taking the case of $\beta_{1}<\left[\beta_{1} \mid \beta_{2}=0\right]$ first, there are two steps to performing the test. First, (10) is estimated twice using Seemingly Unrelated Estimation. The first estimation includes SB and the second excludes it. This generates two sets of parameters and variancecovariance matrices. ${ }^{3}$ Second, a Chi-squared statistic is computed and a test is performed to determine whether the differences between the two estimates of $\beta_{1}$-the first of which left $\beta_{2}$ unrestricted and the second of which restricted it to zero-are statistically significant (see Clogg et al. 1995, for details). Finally, for the case $\beta_{2}>\left[\beta_{2} \mid \beta_{1}=0\right]$ this procedure is then repeated first including and then excluding $\lambda$ at the first step.

\subsection{Data}

\subsubsection{Sample}

Since 1999, the Dutch research institute SEO, in collaboration with the prominent weekly magazine 'Elsevier,' has administered an annual survey designed to measure labor market prospects of recent graduates across colleges and universities in the Netherlands. Respondents fill out extensive questionnaires (two Januarys after graduation) about their tertiary education majors and secondary school grades. Respondents also provide information about their demographic backgrounds, current labor market situations, occupational status (e.g., unemployed, selfemployed, wage-employed), and incomes. Because a measure of risk aversion was obtained only in the January 2004 interviews, we use data from that survey. The final sample comprises 3002 respondents who graduated in 2002 with a Master's degree and who were working as paid employed or self-employed in January 2004.

An advantage of these data is that, consistent with the theory expounded in the previous section, the

\footnotetext{
3 The suest routine implements this procedure in STATA: see Weesie (1999).
}

survey respondents are homogeneous in terms of their education levels and labor market experience. They differ, however, in terms of their investments in balanced skills acquired during their schooling. Moreover, the data are rich enough to measure balanced skills in two distinct ways, as explained below. Furthermore, because SB is determined (both in theory as well as our data sample) prior to occupational choices $z_{i}$, our empirical approach is not vulnerable to the kinds of reverse causality problems that could affect 'conventional' measures of skill balance such as numbers of different prior jobs, for example. Nevertheless, we acknowledge that there might still be unobserved characteristics which are correlated with both SB choices and subsequent $z_{i}$ outcomes. Lacking instrumental variables in our dataset which affect the choice for investing in balanced skills but not the choice of entrepreneurship, we cannot rule out the possibility of endogeneity bias. However, to the best of our knowledge, this limitation affects all empirical work in this area, not just this study.

\subsubsection{Variables}

Occupational choice: self-employment versus wage employment Consistent with the data, we operationalize entrepreneurship as self-employment and use as the dependent variable an indicator variable taking the value one if the respondent is self-employed and zero if they are wage-employed. Many scholars treat self-employment as entrepreneurship (Elfenbein et al. 2010; Folta et al. 2010; Nanda and Sorensen 2010; Astebro et al. 2012). Astebro and Thompson (2011), in investigating the Jack-of-All-Trades and Taste for Variety theories of entrepreneurship, find no qualitative difference in results when entrepreneurship is measured via self-employment, business creation, or business ownership.

According to Table 1, only $2.8 \%$ of the sample was self-employed at the time of the 2004 survey. Low rates of self-employment among recent graduates are commonplace (Dolton and Makepeace 1990), owing to insufficient time for recent graduates to accumulate the financial and social capital needed to make a success of self-employment. In this paper, we trade off our sample's modest post-university self-employment rate for empirically useful homogeneity in human 


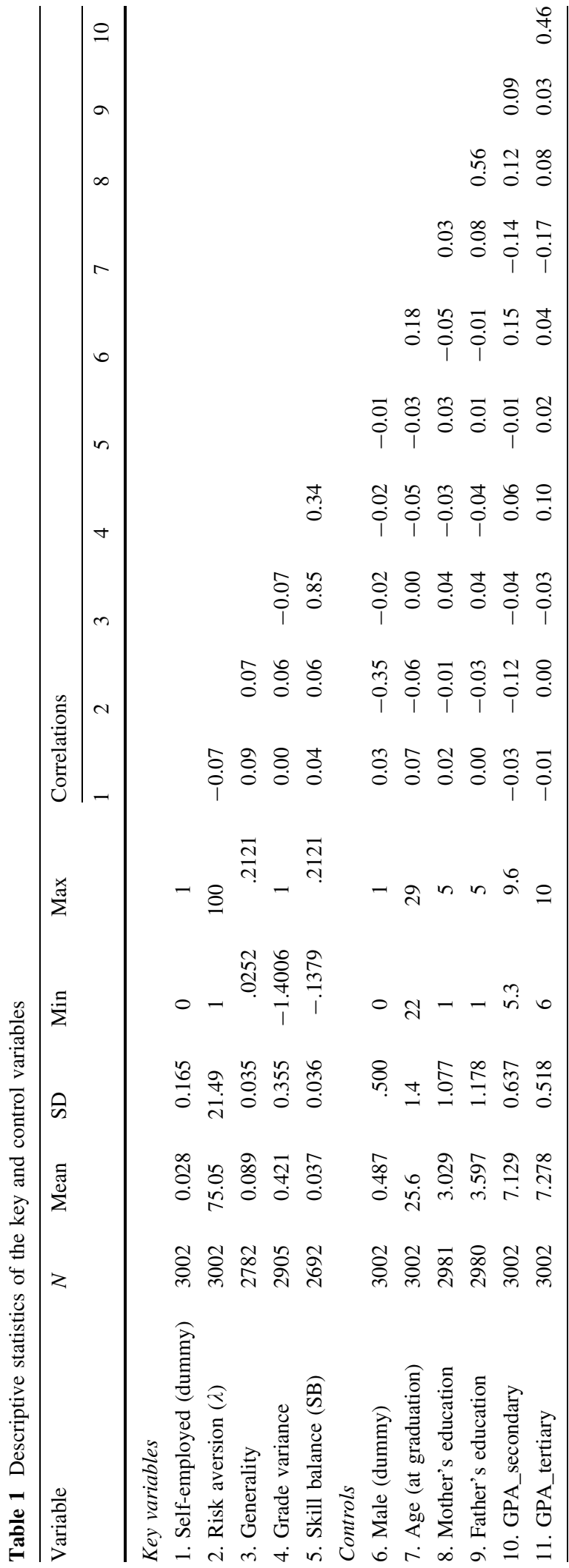

capital as regards educational level and labor market experience.

Risk attitude Respondents were asked to value participation in a hypothetical lottery paying out 1000 euros with a $10 \%$ chance of success. The reservation price $(p)$, i.e., WTP or Willingness to Pay, for participating in such a hypothetical lottery has been shown to be a valid (inverse) indicator of risk aversion and behavior under risk (see Barsky et al. 1997; Cramer et al. 2002; Dohmen et al. 2012). Risk neutrality would imply a reservation price of 100 and risk aversion a price below 100 . We measure risk aversion as $\lambda=100-p$. The average score on this measure of risk aversion is 75.0 (with a standard deviation of 21.5), see Table 1. Furthermore, the average value of $\lambda$ in the subset of self-employed is significantly lower than in the subset of employees $(\lambda=67.4$ vs. $\lambda=75.3, p<0.01)$-in line with earlier applications (Cramer et al. 2002).

Skill balance Our objective is to measure choices of (early) skill balance prior to the acquisition of labor market experience by sample respondents. Our skill balance variable (SB) is computed as the product of two underlying measures. The first underlying measure, 'Generality,' captures the variety of industries that a given degree major is observed to be used in. It therefore captures an 'external,' usage-based aspect of skill versatility. The second underlying measure, 'Grade variance,' records the spread of grades that individuals achieve across three different secondary school courses. It captures an 'internal,' i.e., individual-specific, aspect of balance of innate skill competence.

Generality Some degree majors confer a skill set which is useful in a variety of different industries after graduation, whereas other majors have only a narrow, or specialized, range of applicability. (In our dataset, with only Master's students, we expect that all represented fields of study are adding value to the human capital in the firm.) We define our Generality measure as the total number of distinct industry sectors employing graduates with a given major two years after graduation, scaled by the number of students graduating with that major. To minimize the impact of outliers, we only define this variable for degree fields with more than thirty graduates in the sample. Data on both employees and the self-employed were used to 
construct this measure. Table 5 in Appendix lists all academic majors, the numbers of associated respondents, values of Generality, and self-employment rates. Majors such as sociology, applied computer science, languages and culture have high Generality scores, whereas medical sciences ranks lower. Table 6 in Appendix lists the distinct industry sectors and the number of observations in each sector.

Grade variance This construct measures the variation in grades received by respondents while in secondary school. We posit that grades are an outcome from talent as well as effort to understand course material. Student choices about effort allocation between academic courses therefore provide a partial explanation of grade outcome variance. Some students may choose to build on their strengths, while other students choose to neglect amplifying their strength in favor of reducing the liability of their weakness, thus developing 'well-roundedness.' The smaller is grade variance, the more balanced is a person's foundation of learning skills. Grade variance equates to $1-\operatorname{stdev}(\alpha, \beta, \gamma)$, where $\alpha=$ Grade Point Average (GPA) in humanities and languages, $\beta=$ GPA in hard sciences, and $\gamma=$ GPA in behavioral sciences. Thus greater values of our 'grade variance' operationalization of skills balance corresponds with greater skills balance, not less. The main reason for using this nomenclature is that positive coefficients for either skills balance variables carry the same interpretation.

Skill balance We acknowledge the shortcomings of the Generality and Grade variance measures, especially when either is taken alone. 'Generality' on its own says relatively little about skill balance at the individual level, while 'Grade variance' on its own does not capture the industry context and applicability of diverse skills. ${ }^{4}$ Thus, to improve our operationalization of skill balance, we multiply 'Generality' and 'Grade variance' together to obtain a composite explanatory variable, SB. By combining a measure of skill balance which varies across degree fields with a measure which varies across individuals, SB

\footnotetext{
$\overline{4}$ Previous measures of balanced skills have emphasized individual-level variation, relying heavily on the number of previous job roles (though Lazear 2005, also proposed the diversity of subjects studied at college). Unlike numbers of job roles, our SB variable is not time-varying, so panel data estimation could not be used to control for person-specific fixed effects as in Silva (2007), even if we had a panel.
}

provides a comprehensive overall measure of skill balance obtained from early investments in skills. We believe this is more informative than either of the underlying measures alone. The main tables of results below will present results based on SB, although for completeness the 'Appendix' will also present results obtained for each of the underlying measures.

Control variables Besides the key variables described above, we include a set of control variables including gender, age (varying from 22 to 29), parental education levels (measured on a 1-5 scale), and ability levels. The latter is measured as mean GPA scores both in secondary and in tertiary education, expressed on a scale from 1-10, where 6 is deemed a pass grade in the Netherlands. Table 1 presents descriptive statistics and correlations between the variables. There are no obvious problems of collinearity. Self-employment is correlated negatively with risk aversion and positively with 'Generality' (though not with 'Grade variance'), while risk aversion is associated positively with skill balance. Interestingly, the two main measures of skill balance are negatively correlated, suggesting that they are capturing distinct aspects of SB.

\section{Estimation results}

We first test Proposition 1 by measuring the association between skill balance, SB, and risk aversion, $\lambda$, among employees. Column I of Table 2 presents the results for a 'baseline' specification without control variables. It offers clear support for the proposition that people who are more risk-averse acquire significantly more balanced skill sets. These results continue to hold when control variables are included and alternative estimation methods, namely robust estimation and clustering, are used (columns II-IV). The results for the two underlying SB measures can be found in Appendix Table 7. Across the board, the results support Proposition 1.

Next, we test Proposition 2 by estimating a probit model of self-employment status. The results reported in Table 3 display a significant positive effect from SB. This supports Proposition 2 and is consistent with the BS theory (and Astebro and Thompson (2011) 'taste for variety' argument) - as well as prior empirical findings from Lazear (2005), Wagner (2006) and Astebro and Thompson (2011). The positive 
Table 2 Risk aversion and skill balance (SB) $j=40$ clusters. Absolute

$t$ values are given in parentheses. The sample excludes self-employed entrepreneurs. They are based on robust estimates in specifications I and II and based on clustered estimates in specifications III and IV $* * *, * *, *$ denote significance at the $1 / 5$ / $10 \%$-level

\begin{tabular}{|c|c|c|c|c|}
\hline Variable & $\begin{array}{l}\text { Specification } \\
\text { (I) }\end{array}$ & $\begin{array}{l}\text { Specification } \\
\text { (II) }\end{array}$ & $\begin{array}{l}\text { Specification } \\
\text { (III) }\end{array}$ & $\begin{array}{l}\text { Specification } \\
\text { (IV) }\end{array}$ \\
\hline Risk aversion $(\lambda)$ & $\begin{array}{l}0.0001 * * * \\
(3.020)\end{array}$ & $\begin{array}{l}0.0001 * * * \\
(3.130)\end{array}$ & $\begin{array}{l}0.0001 * * * \\
(2.870)\end{array}$ & $\begin{array}{l}0.0001 * * * \\
(3.310)\end{array}$ \\
\hline Male & & $\begin{array}{c}0.001 \\
(0.700)\end{array}$ & & $\begin{array}{c}0.001 \\
(0.420)\end{array}$ \\
\hline Age (at graduation) & & $\begin{array}{c}-0.001 \\
(1.600)\end{array}$ & & $\begin{array}{r}-0.001 \\
(0.940)\end{array}$ \\
\hline Mother's education & & $\begin{array}{c}0.001 \\
(1.040)\end{array}$ & & $\begin{array}{c}0.001 \\
(0.940)\end{array}$ \\
\hline Father's education & & $\begin{array}{c}0.000 \\
-(0.050)\end{array}$ & & $\begin{array}{c}0.000 \\
(0.060)\end{array}$ \\
\hline GPA_secondary & & $\begin{array}{c}-0.001 \\
-(0.570)\end{array}$ & & $\begin{array}{r}-0.001 \\
(0.580)\end{array}$ \\
\hline GPA_tertiary & & $\begin{array}{c}0.001 \\
(0.440)\end{array}$ & & $\begin{array}{c}0.001 \\
(0.530)\end{array}$ \\
\hline Constant & $\begin{array}{l}0.029 * * * \\
(11.94)\end{array}$ & $\begin{array}{l}0.047 * * \\
(2.51)\end{array}$ & $\begin{array}{l}0.029 * * * \\
(11.18)\end{array}$ & $\begin{array}{r}0.047 \\
(1.63)\end{array}$ \\
\hline$N$ & 2619 & 2596 & 2619 & 2596 \\
\hline$R^{2}$ & 0.033 & 0.0055 & 0.0033 & 0.0055 \\
\hline$F$ & 9.14 & 2.27 & 8.25 & 2.14 \\
\hline $\operatorname{Pr}>F$ & 0.0025 & 0.0268 & 0.0065 & 0.0619 \\
\hline Control variables included & No & Yes & No & Yes \\
\hline Robust estimation & Yes & Yes & No & No \\
\hline Clustered estimation $(j=40)$ & No & No & Yes & Yes \\
\hline
\end{tabular}

Table 3 Self-employed entrepreneurship, risk aversion and skill balance (SB)

\begin{tabular}{|c|c|c|c|c|c|c|}
\hline & $\begin{array}{l}\text { Specification } \\
\text { (I) }\end{array}$ & $\begin{array}{l}\text { Specification } \\
\text { (II) }\end{array}$ & $\begin{array}{l}\text { Specification } \\
\text { (III) }\end{array}$ & $\begin{array}{l}\text { Specification } \\
\text { (IV) }\end{array}$ & $\begin{array}{l}\text { Specification } \\
\text { (V) }\end{array}$ & $\begin{array}{l}\text { Specification } \\
\text { (VI) }\end{array}$ \\
\hline SB & $\begin{array}{l}2.5818^{*} \\
(1.94)\end{array}$ & $\begin{array}{l}2.7175^{* *} \\
(2.08)\end{array}$ & $\begin{array}{l}2.9830 * * \\
(2.16)\end{array}$ & $\begin{array}{l}3.0573 * * \\
(2.29)\end{array}$ & & \\
\hline Risk aversion $(\lambda)$ & & & $\begin{array}{l}-0.0073 * * * \\
(3.29)\end{array}$ & $\begin{array}{l}-0.0075 * * * \\
(3.32)\end{array}$ & $\begin{array}{l}-0.0064 * * * \\
(3.20)\end{array}$ & $\begin{array}{l}-0.0060 * * * \\
(2.68)\end{array}$ \\
\hline$N$ & 2692 & 2669 & 2692 & 2669 & 3002 & 2975 \\
\hline pseudo $-R^{2}$ & 0.0058 & 0.0313 & 0.0230 & 0.0458 & 0.0129 & 0.0313 \\
\hline Wald $\chi^{2}$ & 3.78 & 27.00 & 13.00 & 38.99 & 9.91 & 23.93 \\
\hline $\operatorname{Pr}>\chi^{2}$ & 0.0520 & 0.0003 & 0.0015 & 0.0000 & 0.0016 & 0.0012 \\
\hline Control variables included & No & Yes & No & Yes & No & Yes \\
\hline Robust estimation & No & No & No & No & Yes & Yes \\
\hline Clustered estimation $(j=40)$ & Yes & Yes & Yes & Yes & No & No \\
\hline
\end{tabular}

$j=40$ clusters. Absolute $t$ values are given in parentheses. The results for specifications I-IV are obtained by clustered estimation methods where each cluster is an education degree field (with $n_{j}>30$ observations). The results are similar when applying robust estimation instead of clustered estimation. Specifications V-VI do not include variables that require clustering

***, **, * denote significance at the 1/5/10 \%-level. The controls included in specifications II, IV and VI are the same as in Table 2 
association between balanced skills and self-employment status hold irrespective of whether control variables are included (specifications II and IV) or not (specifications I and III). Including the risk aversion variable, $\lambda$, does not change this result either (compare specifications I and II with III and IV). The results continue to hold using the underlying measure 'Generality,' but not using the underlying measure 'Grade variance' (see Appendix Table 8 for details).

Table 3 reveals a significant negative association between risk aversion and self-employment. This result is consistent with both the RA theory and Proposition 3(a). The significantly negative association persists irrespective of whether we include control variables [specifications IV and VI] or a measure of balanced skills [specifications III and IV]. In addition, the same results hold when the underlying measures of balanced skills are used instead of SB (see Appendix Table 8).

To obtain an indicator of the economic significance of the result, we have calculated the marginal effect of the probit estimates, evaluated at the mean values of all the independent variables, for the fourth (most parsimonious) specification in Table 3. At the mean level of 'balanced skills,' a one standard deviation in balanced skills (0.035) is associated with an increase in the likelihood of self-employment of $0.6 \%$. At first sight that may seem small; however, in the same specification the predicted likelihood of self-employment (also evaluated at the sample means of all independent variables) is $2.3 \%$. The percentage increase in the likelihood of self-employment associated with a one standard deviation increase in balanced skills is therefore $26 \%$, which is substantial. The corresponding percentage increase in the likelihood of self-employment associated with a decrease of one standard deviation in the measure of risk aversion (21.49) is even greater, at $38 \%$. Hence the measured effects are not only statistically significant, but also economically meaningful.

We also estimated Table 3 using a linear probability model (LPM) as an alternative to the probit model as a way of testing the robustness of the results (that have been obtained with relatively few clustered groups). Appendix Table 9 presents the LPM results. The similarity of these results to what we show in the main table suggests robustness. The signs and significance levels of the variables are similar in both tables. Moreover, comparing the marginal effects derived
Table 4 Testing the indirect effect of risk aversion on selfemployment

\begin{tabular}{lll}
\hline$\chi^{2}$-test & $\begin{array}{l}\text { Specification } \\
\text { (I) }\end{array}$ & $\begin{array}{l}\text { Specification } \\
(\mathrm{II})\end{array}$ \\
\hline $\begin{array}{l}\text { Proposition } 3 \mathrm{~b} \\
\quad \beta_{2}>\beta_{2} \mid \beta_{1}=0\end{array}$ & \\
$\quad \chi^{2}$ & $4.18^{* *}$ & $3.96^{* *}$ \\
$P$ value & 0.0410 & 0.0465 \\
$N$ & 2692 & 2669 \\
Corrolary & & \\
$\beta_{1}<\beta_{1} \mid \beta_{2}=0$ & & \\
$\chi^{2}$ & $5.55^{* *}$ & $12.34 * * *$ \\
$P$ value & 0.0185 & 0.0004 \\
$N$ & 3002 & 2975 \\
Control variables included & No & Yes \\
Clustered estimation $(j=40)$ & Yes & Yes \\
\hline
\end{tabular}

$* * *, * *, *$ denotes significance at the $1 / 5 / 10 \%$-level

from the probit estimates to the LPM coefficients shows that the magnitudes of the estimated associations are similar too.

As noted in Sect. 2, Proposition 3(b) follows logically from Propositions 1 and 2, both of which received empirical support above. And as noted in Sect. 3, an implication of Proposition 3(b) is that excluding SB from (10) will increase the estimate of $\beta_{1}$ in this equation, while excluding $\lambda$ from (10) will reduce the estimate of $\beta_{2}$. Inspection of Table 3 indicates that the coefficients change in the expected directions when these exclusion restrictions are imposed. But are these differences statistically significant? To answer this question, we adopt the testing approach outlined in the previous section and report the $\chi^{2}$ statistics in Table 4 . These results clearly show that the expected biases are statistically significant.

With regard to the relationship between risk and balanced skills, it is helpful to compare our findings with those of Lazear (2005) and Astebro and Thompson (2011). First, although Lazear (2005) measured risk tolerance, whereas we measured risk aversion, adding these different risk variables affected the skill balance coefficient in a similar direction and magnitude. Lazear's skill balance coefficient adjusted by $10.2 \%$, while ours adjusted in the same direction by $12.5 \%$. While we cannot verify the statistical significance of the difference in magnitudes of the coefficients on balanced skills for Lazear (2005), in our case 
the difference is statistically significant. Second, Astebro and Thompson (2011) found that risk aversion decreased the probability of choosing entrepreneurship and decreased skill balance as well. The discrepancy between our findings and those from Astebro and Thompson (2011) is striking. Several reasons could explain this, including differences in the data samples and random effects, for example. Another possibility, however, is that Astebro and Thompson (2011) used a measure of risk aversion which is sensitive to career context. Specifically, they measured risk aversion by such survey items as 'I would participate only in business undertakings that are relatively certain' and 'I probably would not take the chance of borrowing money for a business deal even if it might be profitable.' They remarked that 'it appears that those who are more risk-averse are less likely to become entrepreneurs, less likely to choose a variety of jobs, and less likely to earn a high income' (2011: 646). We believe that there may be an alternative explanation: that those who have (already) chosen to specialize, based on gradual realization or identification of the domains in which their strengths lie, will be biased against taking risks in domains where they themselves have realized they are weak.

Finally, if risk aversion has a negative direct, and a positive indirect, effect on entrepreneurship, what is the overall (net) effect and how does it vary across sample cases? The estimated net effect of risk aversion on entrepreneurship is certainly negative at the sample mean; but it turns out to be positive for $12 \%$ of the sample cases. For these cases, the impact of risk aversion on the acquisition of balanced skills is so powerful that it actually turns risk aversion into a force promoting entrepreneurship.

\section{Conclusion}

A popular economic theory of entrepreneurship is that risk aversion decreases the likelihood of entrepreneurship. More recently, researchers have begun to embrace Lazear (2005) theory predicting that balanced skills increase the likelihood of entrepreneurship. Despite these clear-cut theoretical predictions, empirical estimates of the effects of risk attitude and skills balance on entrepreneurship choices have been mixed. This paper has presented a two-stage theory of choices of skill balance and occupational choice which unify these two (hitherto weakly connected) strands of theoretical work, and which may help explain the inconclusive nature of prior empirical findings. In contrast to research endowing skill balance and risk with only independent effects, we have argued that accurate estimation needs to take into account a possible mediating relationship between these two constructs. We propose that by making the acquisition of balanced skills more attractive, risk aversion can even end up as a positive force promoting entrepreneurship — contrary to what might be expected from theories of RA which ignore BS arguments.

Our measures of skill balance have enabled us to conduct a first test of our theory, using two different measures of skill balance: industry applicability of university majors, and variance in grades across basic coursework in secondary school. These measures have the advantage of occurring prior to occupational choices, though they might still be prone to endogeneity. We leave it to future research to propose and investigate other possible variables which might be free of possible endogeneity bias. We also leave it to future research to investigate how the addition of variables such as personality, access to capital and prospective entrepreneurial setup costs might influence the relationships among risk aversion, skill balance, and entrepreneurship.

Nevertheless, our arguments and empirical findings may command interest beyond the community of entrepreneurship scholars, including among practitioners and entrepreneurs. Our results reveal, perhaps surprisingly, that some risk-averse people, long deemed inherently ill-suited to entrepreneurship, might actually be well-suited to this occupation after all. This insight could have implications for entrepreneurship educators, who often stress the 'negative' aspects of risk aversion for entrepreneurship without suggesting any positive aspects. It is also possible that young people underestimate the future value of acquiring balanced skills, for instance by discounting the possibility of turning entrepreneur later in life. Our research suggests that the acquisition of balanced skills could be usefully encouraged at school and university since it builds a valuable future option for students.

It is also possible that some cultures or environments succeed, either deliberately or otherwise, in fostering balanced skills among their population, or in channeling risk aversion into the acquisition of balanced skills. For instance, formal education and corporate management 
training programs are known to differ in their emphasis on specialized relative to balanced skill acquisition, or in the temporality of such acquisition (Hsieh 2016). If governments genuinely wish to encourage entrepreneurship, a less specialized school curriculum might be one indirect, and long-term, way of doing so. Conversely, for firms concerned about losing employees to entrepreneurship (Hellmann 2007), specialists might be favored over job candidates with balanced skills. Extending the logic in this paper, one is led to wonder whether there might be other counterintuitive indirect relationships between balanced skills and individuals' preferences or personality traits. For example, people who have a 'need for achievement' may spend a decade and longer in a single field of study in order to attain the requisite expertise (Simon and Gilmartin 1973). In contrast, those who have no such need for achievement may dabble in whatever interests come their way, culminating in a balanced skill profile. The same could be true of unconfident people having low expectations of their success or the rate of return to their human capital. Instead of being jacks-of-all-trades, such individuals might behave more like Astebro and Thompson (2011) 'hobos.' It would be interesting to explore how these personality factors interface with skill acquisition at school and university, varied job experience afterward, and also participation in entrepreneurship. We leave this issue for future research.

To conclude, this paper has proposed a novel linkage between risk aversion and balanced skills which casts theories of entrepreneurial selection in a new light. The paper also carries implications for scholars concerned with interpreting the body of evidence on risk aversion and balanced skills theories of entrepreneurship. And finally, its findings should interest practitioners and educators who seek to promote entrepreneurship as an occupational choice.

Open Access This article is distributed under the terms of the Creative Commons Attribution 4.0 International License (http:// creativecommons.org/licenses/by/4.0/), which permits unrestricted use, distribution, and reproduction in any medium, provided you give appropriate credit to the original author(s) and the source, provide a link to the Creative Commons license, and indicate if changes were made.

\section{Appendix}

See Tables 5, 6, 7, 8 and 9.

Table 5 Key variables (mean) by degree field

\begin{tabular}{|c|c|c|c|c|c|c|c|}
\hline Degree field (sample size) & Generality & $\begin{array}{l}\text { Fraction } \\
\text { Self- } \\
\text { employed }\end{array}$ & $\begin{array}{l}\text { Risk } \\
\text { aversion }\end{array}$ & $\begin{array}{l}\text { Degree field } \\
\text { (sample size) }\end{array}$ & Generality & $\begin{array}{l}\text { Fraction } \\
\text { Self- } \\
\text { employed }\end{array}$ & $\begin{array}{l}\text { Risk } \\
\text { aversion }\end{array}$ \\
\hline Dutch (40) & 0.15 & 0.13 & 86.18 & Applied Comp Sciences (48) & 0.15 & 0.02 & 77.54 \\
\hline English (37) & 0.14 & 0.03 & 87.62 & Applied Math/Physics (73) & 0.11 & 0.01 & 72.78 \\
\hline Other Languages (30) & - & 0.07 & 84.50 & Economics (104) & 0.07 & 0.02 & 59.72 \\
\hline Philosophy, Theology (25) & - & 0.04 & 79.76 & Management Studies (126) & 0.06 & 0.01 & 71.55 \\
\hline History (62) & 0.08 & 0.06 & 80.63 & Econometrics (67) & 0.10 & 0.01 & 54.52 \\
\hline $\begin{array}{l}\text { Language and Culture, General } \\
\text { (33) }\end{array}$ & 0.21 & 0.12 & 88.52 & Fiscal Economics (24) & - & 0.00 & 58.96 \\
\hline History of Art (28) & - & 0.11 & 80.00 & Business Studies (80) & 0.09 & 0.08 & 65.66 \\
\hline Corporate Communication (19) & - & 0.00 & 78.95 & Dutch Law (107) & 0.06 & 0.01 & 74.56 \\
\hline Film, Television, Theater (26) & - & 0.08 & 92.77 & Notarial Law (48) & 0.08 & 0.00 & 77.77 \\
\hline Alpha Information Sciences (70) & 0.10 & 0.03 & 71.41 & Fiscal Law (69) & 0.07 & 0.01 & 71.30 \\
\hline Chemistry (38) & 0.11 & 0.00 & 81.63 & Health Studies (103) & 0.07 & 0.02 & 80.81 \\
\hline Computer Science (34) & 0.15 & 0.03 & 73.79 & Medical Science (119) & 0.03 & 0.00 & 77.54 \\
\hline Biology (104) & 0.07 & 0.05 & 80.63 & Biomedical Science (84) & 0.07 & 0.00 & 81.81 \\
\hline Pharmacy (36) & 0.14 & 0.06 & 69.44 & Veterinary Science (29) & - & 0.03 & 82.38 \\
\hline Theor. Math \& Physics (53) & 0.11 & 0.00 & 62.87 & Sociology (32) & 0.19 & 0.09 & 76.72 \\
\hline Gen. Applied Earth Science (37) & 0.16 & 0.05 & 83.19 & Psychology (112) & 0.06 & 0.00 & 82.44 \\
\hline Bioprocessing \& Food Tech (80) & 0.09 & 0.00 & 83.19 & Politicology (36) & 0.19 & 0.03 & 80.28 \\
\hline Building Engineering \& Arch (92) & 0.07 & 0.07 & 76.27 & Pedagogy (77) & 0.10 & 0.00 & 80.16 \\
\hline Mechanical Engineering (80) & 0.08 & 0.00 & 65.86 & Applied Education Studies (43) & 0.14 & 0.02 & 86.12 \\
\hline
\end{tabular}


Table 5 continued

\begin{tabular}{|c|c|c|c|c|c|c|c|}
\hline Degree field (sample size) & Generality & $\begin{array}{l}\text { Fraction } \\
\text { Self- } \\
\text { employed }\end{array}$ & $\begin{array}{l}\text { Risk } \\
\text { aversion }\end{array}$ & $\begin{array}{l}\text { Degree field } \\
\text { (sample size) }\end{array}$ & Generality & $\begin{array}{l}\text { Fraction } \\
\text { Self- } \\
\text { employed }\end{array}$ & $\begin{array}{l}\text { Risk } \\
\text { aversion }\end{array}$ \\
\hline Electrical Engineering (53) & 0.11 & 0.02 & 68.49 & Cultural Anthropology (24) & - & 0.00 & 84.33 \\
\hline Chemical Engineering (42) & 0.10 & 0.00 & 79.57 & Communication Sciences (67) & 0.10 & 0.01 & 77.24 \\
\hline Civil Engineering (91) & 0.07 & 0.03 & 65.13 & $\begin{array}{l}\text { Social-cultural Mgmt Studies } \\
\text { (88) }\end{array}$ & 0.09 & 0.01 & 78.13 \\
\hline Technology \& Management (90) & 0.08 & 0.01 & 62.19 & Public Management (93) & 0.06 & 0.03 & 76.23 \\
\hline Industrial Design (50) & 0.12 & 0.22 & 70.60 & Social Geography (84) & 0.08 & 0.01 & 73.37 \\
\hline \multirow[t]{2}{*}{ Aerospace Engineering (15) } & - & 0.00 & 89.67 & & & & \\
\hline & & & & Average & 0.09 & 0.03 & 75.05 \\
\hline
\end{tabular}

Table 6 Industries

\begin{tabular}{ll}
\hline Industry & $N$ \\
\hline Public Sector & 303 \\
Education & 629 \\
Business Service & 728 \\
Financial Service & 137 \\
Health Sector & 475 \\
Manufacturing & 264 \\
Retail and other & 457 \\
\hline
\end{tabular}

Table 7 Risk aversion and alternative measures of skill balance $j=40$ clusters. Absolute $t$ values are given in parentheses. The sample excludes self-employed entrepreneurs. They are based on robust estimates in specifications I and II and based on clustered estimates in specifications III and IV $* * *, * *, *$ denote significance at the $1 / 5$ / $10 \%$-level

\begin{tabular}{|c|c|c|c|c|}
\hline & $\begin{array}{l}\text { Specification } \\
\text { (I) }\end{array}$ & $\begin{array}{l}\text { Specification } \\
\text { (II) }\end{array}$ & $\begin{array}{l}\text { Specification } \\
\text { (III) }\end{array}$ & $\begin{array}{l}\text { Specification } \\
\text { (IV) }\end{array}$ \\
\hline Panel A & \multicolumn{4}{|l|}{ Generality } \\
\hline Risk aversion $(\lambda)$ & $\begin{array}{l}0.0001^{* * * *} \\
(3.29)\end{array}$ & $\begin{array}{l}0.0001^{* * * *} \\
(3.39)\end{array}$ & $\begin{array}{l}0.0001 \\
(1.28)\end{array}$ & $\begin{array}{l}0.0001^{*} \\
(1.68)\end{array}$ \\
\hline$N$ & 2707 & 2682 & 2707 & 2682 \\
\hline$R^{2}$ & 0.036 & 0.018 & 0.0036 & 0.0018 \\
\hline$F$ & 10.80 & 7.24 & 1.65 & 2.48 \\
\hline $\operatorname{Pr}>F$ & 0.0010 & 0.0000 & 0.2064 & 0.0329 \\
\hline Panel B & \multicolumn{4}{|c|}{ Grade variance } \\
\hline Risk aversion $(\lambda)$ & $\begin{array}{l}0.0007 * * \\
(2.27)\end{array}$ & $\begin{array}{l}0.0008^{* *} \\
(2.35)\end{array}$ & $\begin{array}{l}0.0007^{*} \\
(1.90)\end{array}$ & $\begin{array}{l}0.0008^{* *} \\
(2.49)\end{array}$ \\
\hline$N$ & 2823 & 2798 & 2823 & 2798 \\
\hline$R^{2}$ & 0.0018 & 0.0050 & 0.0018 & 0.0050 \\
\hline$F$ & 5.15 & 1.94 & 3.59 & 2.48 \\
\hline $\operatorname{Pr}>F$ & 0.0234 & 0.0595 & 0.0641 & 0.0297 \\
\hline Control variables included & No & Yes & No & Yes \\
\hline Robust estimation & Yes & Yes & No & No \\
\hline Clustered estimation $(j=40)$ & No & No & Yes & Yes \\
\hline
\end{tabular}


Table 8 Self-employed entrepreneurship, risk aversion and skill balance (alternative measures)

\begin{tabular}{|c|c|c|c|c|c|c|c|c|}
\hline \multirow[t]{2}{*}{ Measure of skill balance } & \multicolumn{4}{|l|}{ Generality } & \multicolumn{4}{|c|}{ Grade variance } \\
\hline & $\begin{array}{l}\text { Spec } \\
\text { (I) }\end{array}$ & $\begin{array}{l}\text { Spec } \\
\text { (II) }\end{array}$ & $\begin{array}{l}\text { Spec } \\
\text { (III) }\end{array}$ & $\begin{array}{l}\text { Spec } \\
\text { (IV) }\end{array}$ & $\begin{array}{l}\text { Spec } \\
\text { (I) }\end{array}$ & $\begin{array}{l}\text { Spec } \\
\text { (II) }\end{array}$ & $\begin{array}{l}\text { Spec } \\
\text { (III) }\end{array}$ & $\begin{array}{l}\text { Spec } \\
\text { (IV) }\end{array}$ \\
\hline Skill balance & $\begin{array}{l}5.640 * * * \\
(3.91)\end{array}$ & $\begin{array}{l}5.924 * * * \\
(4.18)\end{array}$ & $\begin{array}{l}6.389 * * * \\
(4.09)\end{array}$ & $\begin{array}{l}6.440 * * * \\
(4.29)\end{array}$ & $\begin{array}{r}-0.077 \\
(0.58)\end{array}$ & $\begin{array}{c}-0.096 \\
(0.71)\end{array}$ & $\begin{array}{r}-0.060 \\
(0.49)\end{array}$ & $\begin{array}{r}-0.080 \\
(0.59)\end{array}$ \\
\hline Risk aversion $(\lambda)$ & & & $\begin{array}{l}-0.0083^{* * *} \\
(4.36)\end{array}$ & $\begin{array}{l}-0.0083^{* * *} \\
(3.93)\end{array}$ & & & $\begin{array}{l}-0.0063^{* * *} \\
2.96)\end{array}$ & $\begin{array}{c}-0.0059 * * * \\
(2.61)\end{array}$ \\
\hline$N$ & 2782 & 2757 & 2782 & 2757 & 2905 & 2880 & 2905 & 2880 \\
\hline pseudo $-R^{2}$ & 0.0293 & 0.0571 & 0.0509 & 0.0744 & 0.0005 & 0.0223 & 0.0130 & 0.0313 \\
\hline Wald $\chi^{2}$ & 15.30 & 52.17 & 29.29 & 61.80 & 0.34 & 16.64 & 9.87 & 23.29 \\
\hline $\operatorname{Pr}>\chi^{2}$ & 0.0001 & 0.0000 & 0.0000 & 0.0000 & 0.5604 & 0.0199 & 0.0072 & 0.0030 \\
\hline Control variables included & No & Yes & No & Yes & No & Yes & No & Yes \\
\hline Robust estimation & No & No & No & No & Yes & Yes & Yes & Yes \\
\hline Clustered estimation $(j=40)$ & Yes & Yes & Yes & Yes & No & No & No & No \\
\hline
\end{tabular}

$\overline{j=40 \text { clusters. Absolute } t \text { values are given in parentheses. The results for specifications I-IV are obtained by clustered estimation }}$ methods where each cluster is an education degree field (with $n_{j}>30$ observations) when using BS_tertiary as the measure of skill balance. Robust estimates are shown when using BS_secondary as the measure of skill balance. The results are similar when applying robust (clustered) estimation instead of clustered (robust) estimation

$* * *, * *, *$ denote significance at the $1 / 5 / 10 \%$-level. The controls included in specifications II and IV are the same as in Table 2

Table 9 Self-employed entrepreneurship, risk aversion and skill balance: linear probability model estimates

\begin{tabular}{|c|c|c|c|c|c|c|}
\hline & $\begin{array}{l}\text { Specification } \\
\text { (I) }\end{array}$ & $\begin{array}{l}\text { Specification } \\
\text { (II) }\end{array}$ & $\begin{array}{l}\text { Specification } \\
\text { (III) }\end{array}$ & $\begin{array}{l}\text { Specification } \\
\text { (IV) }\end{array}$ & $\begin{array}{l}\text { Specification } \\
\text { (V) }\end{array}$ & $\begin{array}{l}\text { Specification } \\
\text { (VI) }\end{array}$ \\
\hline \multirow[t]{2}{*}{ SB } & $0.1786^{*}$ & $0.1867 *$ & $0.1968 * *$ & $0.2039 * *$ & & \\
\hline & $(1.80)$ & $(1.89)$ & $(2.00)$ & $(2.07)$ & & \\
\hline \multirow[t]{2}{*}{ Risk aversion $(\lambda)$} & & & $-0.0005 * * *$ & $-0.0005 * * *$ & $-0.0005 * * *$ & $-0.0004 * * *$ \\
\hline & & & $(2.77)$ & $(2.71)$ & $(3.34)$ & $(2.84)$ \\
\hline$N$ & 2692 & 2669 & 2692 & 2669 & 3002 & 2975 \\
\hline$R^{2}$ Adj. & 0.0012 & 0.0055 & 0.0055 & 0.009 & 0.0034 & 0.0061 \\
\hline Control variables included & No & Yes & No & Yes & No & Yes \\
\hline Robust estimation & No & No & No & No & Yes & Yes \\
\hline Clustered estimation $(j=40)$ & Yes & Yes & Yes & Yes & No & No \\
\hline
\end{tabular}

See the notes below Table 3

\section{References}

Abernathy, W. J., \& Wayne, K. (1974). Limits of the learning curve. Harvard Business Review, 52(5), 109-119.

Ahn, T. (2010). Attitudes toward risk and self-employment of young workers. Labour Economics, 17, 434-442.

Amihud, Y., \& Lev, B. (1981). Risk reduction as a managerial motive for conglomerate mergers. Bell Journal of Economics, 12, 605-617.

Astebro, T., \& Thompson, P. (2011). Entrepreneurs: Jacks of all trades or hobos? Research Policy, 40, 637-649.
Astebro, T., Chen, J., \& Thompson, P. (2012). Stars and misfits: A theory of occupational choice. Management Science, 57(11), 1999-2017.

Barsky, R. B., Juster, F. T., Kimball, M. S., \& Shapiro, M. D. (1997). Preference parameters and behavioral heterogeneity: An experimental approach in the health and retirement study. Quarterly Journal of Economics, 112(2), 537-579

Brockhaus, R. H. (1980). Risk taking propensity of entrepreneurs. Academy of Management Journal, 23, 20-509.

Brown, S., Dietrich, M., Ortiz-Nunez, A., \& Taylor, K. (2011). Self-employment and attitudes towards risk: Timing and 
unobserved heterogeneity. Journal of Economic Psychology, 32, 33-425.

Clogg, C. C., Petkova, E., \& Haritou, A. (1995). Statistical methods for comparing regression coefficients between models. American Journal of Sociology, 100, 1261-1293.

Cramer, J. S., Hartog, J., Jonker, N., \& van Praag, C. M. (2002). Low risk aversion encourages the choice for entrepreneurship: An empirical test of a truism. Journal of Economic Behavior \& Organization, 48, 29-36.

Dohmen, T., Falk, A., \& Sunde, U. (2012). The intergenerational transmission of risk and trust attitudes. Review of Economic Studies, 79(2), 77-645.

Dolton, P. J., \& Makepeace, G. H. (1990). Self-employment among graduates. Bulletin of Economic Research, 42, $35-53$.

Ekelund, J., Johansson, E., Jarvelin, M.-R., \& Lichtermann, D. (2005). Self-employment and risk-aversion-Evidence from psychological test data. Labour Economics, 12, 649-659.

Elfenbein, D., Hamilton, B., \& Zenger, T. R. (2010). The small firm effect and the entrepreneurial spawning of scientists and engineers. Management Science, 56(4), 659-681.

Elston, J. A., Harrison, G. W., \& Rutstrom, E. E. (2005). Characterizing the entrepreneur using field experiments. Working paper, University of Central Florida.

Folta, T. B., Delmar, F., \& Wennberg, K. (2010). Hybrid entrepreneurship. Management Science, 56(2), 69-253.

Greene, W. H. (2003). Econometric analysis (5th ed.). New Jersey: Prentice-Hall.

Hartog, J., van Praag, C. M., \& Van der Sluis, J. (2010). If you are so smart, why aren't you an entrepreneur? Returns to cognitive and social ability: Entrepreneurs versus employees. Journal of Economics \& Management Strategy, 19(4), 947-989.

Hellmann, T. (2007). When do employees become entrepreneurs? Management Science, 53(6), 33-919.

Hsieh, C. (2016). Do the self-employed more likely emerge from sequential or parallel work experience in businessrelated functions? Entrepreneurship Theory \& Practice, 40(2), 34-307.

Kihlstrom, R. E., \& Laffont, J. J. (1979). A general equilibrium entrepreneurial theory of firm formation based on risk aversion. Journal of Political Economy, 87, 49-719.
Lazear, E. (2005). Entrepreneurship. Journal of Labor Economics, 23, 649-680.

Miner, J. B., \& Raju, N. S. (2004). Risk propensity differences between managers and entrepreneurs and between low- and high-growth entrepreneurs: A reply in a more conservative vein. Journal of Applied Psychology, 89(1), 3-13.

Nanda, R., \& Sorensen, J. B. (2010). Workplace peers and entrepreneurship. Management Science, 56(7), 26-1116.

Parker, S. C. (1997). The effects of risk on self-employment. Small Business Economics, 9(6), 512-522.

Parker, S. C. (2008). Entrepreneurship among married couples in the United States: A simultaneous probit approach. Labour Economics, 15(3), 37-515.

Polkovnichenko, V. (2002). Human capital and the private equity premium. Federal Reserve Bank Working Paper.

Sargent, T. (1987). Macroeconomic theory (2nd ed.). New York: Academic Press.

Shaver, K. G., \& Scott, L. R. (1991). Person, process, choice: The psychology of new venture creation. Entrepreneurship Theory \& Practice, 16, 23-45.

Silva, O. (2007). The jack-of-all-trades entrepreneur: Innate talent or acquired skill? Economics Letters, 97, 118-123.

Simon, H. A., \& Gilmartin, K. J. (1973). A simulation of memory for chess positions. Cognitive Psychology, 5, 29-46.

Simons, K. L., \& Astebro, T. (2010). Entrepreneurs seeking gains: Profit motives and risk aversion in inventors' commercialization decisions. Journal of Economics \& Management Strategy, 19(4), 863-888.

Stewart, W. H, Jr., \& Roth, P. L. (2001). Risk propensity differences between entrepreneurs and managers: A metaanalytic review. Journal of Applied Psychology, 86(1), 53-145.

Wagner, J. (2006). Are nascent entrepreneurs 'jacks-of-alltrades'? A test of Lazear's theory of entrepreneurship with German data. Applied Economics, 38, 2415-2419.

Weesie, J. (1999). sg121: Seemingly unrelated estimation and the cluster-adjusted sandwich estimator. Stata Technical Bulletin, 52, 34-47 